\title{
The Effect of Off-Spec Canola Biodiesel Blending on Fuel Properties for Cold Weather Applications
}

\author{
Ubaid Hassan (D), Isam Al-Zubaidi * and Hussameldin Ibrahim * (D) \\ Process Systems Engineering, Faculty of Engineering and Applied Science, University of Regina, 3737 Wascana \\ Parkway, Regina, SK S4S 0A2, Canada; ubaidhassan2004@gmail.com \\ * Correspondence: isam.al.zubaidi@uregina.ca (I.A.-Z.); hussameldin.ibrahim@uregina.ca (H.I.); \\ Tel.: +1-306-337-3126 (I.A.-Z.); +1-306-337-3347 (H.I.)
}

Received: 12 February 2018; Accepted: 29 June 2018; Published: 2 July 2018

\begin{abstract}
Biodiesel is a renewable and reduced-emission alternative fuel produced mainly from the alcoholysis of vegetable oils and/or animal fats. It is mainly used in blends with diesel fuel to reduce emissions, enhance lubrication and lower sulfur content. Being able to accurately determine the physicochemical properties of blended fuel is important for optimal injection, combustion, and lubricating performance in diesel engines. Also, fuel properties vary as the ratio of biodiesel-diesel changes, affecting the final fuel quality. In this study, a wide range and narrow intervals of $(0,2,4$, $6,8,10,12,15,18,20,25,35,50,75$ and $100 \%$ by volume) off-quality canola-based biodiesel blends were prepared at ambient conditions and used to study the blended fuel properties (density, kinematic viscosity, flash point, cloud point and pour point). This is particularly important for examining the effect of a biodiesel content of more than $20 \%$-the industry maximum blend content-on cold flow properties, fuel stability, energy value, and emissions. It was found that the kinematic viscosity and density increased linearly as the concentration of the biodiesel in the blend increases. The pour point and cloud point temperature showed a small increase up to $35 \%$ blending ratio and a rapid increase in temperature for biodiesel concentrations higher than $35 \%$. Also, the flash point remained almost constant at an average value of $73{ }^{\circ} \mathrm{C}$ for blends less than $20 \%$, above which the values for the flash point increased exponentially with biodiesel concentration. Furthermore, predictive correlations were developed for all tested fuel properties from regressing corresponding experimental data. All models exhibited excellent agreement with experimental data with an average absolute deviation of less than $5 \%$.
\end{abstract}

Keywords: biodiesel blending; low quality canola; reduced emissions; fuel properties; experimental study; regression models

\section{Introduction}

Biodiesel is a long chain fatty acid ester mainly produced from reacting vegetable oils and/or animal fats with alcohol (methanol or ethanol) in the presence of a strong base catalyst $(\mathrm{NaOH}$ or $\mathrm{KOH}$ ). It is considered a biodegradable environmentally friendly fuel that has similar properties to petrodiesel. Biodiesel is typically used as a blending agent to improve the combustion and lubricating quality of convectional diesel fuel. Also, biodiesel does not contain a detectable amount of sulfur and is considered carbon neutral due to its closed carbon cycle [1]. Evaluating the biodiesel-diesel blended fuel properties is of utmost importance for choosing a suitable blending ratio in order to meet the required blended fuel standard [2]. This work proposes an alternative method for estimating the bulk modulus of biodiesel-diesel fuel blends by means of experimental investigation commonly used for determining fuel properties. 
The literature shows that biodiesel-diesel blend concentrations of $10 \%$ by volume (B10) have no significant effect on the density and viscosity of the blended fuel at temperatures of $20{ }^{\circ} \mathrm{C}$ to $80^{\circ} \mathrm{C}$ [3]. For higher concentrated blends with concentrations of B20, the density was found to vary with temperature according to the correlation given by Equation (1):

$$
\rho=0.0007 \cdot T+0.8696
$$

where $\rho$ is the fuel density and $T$ is the system temperature. Equation (2) describes a power-fitting correlation between the dynamic viscosity $(\mu)$ and temperature:

$$
\mu=c \cdot T \cdot d
$$

where $v$ is the fuel dynamic viscosity $(\mathrm{cP}), c$ and $d$ are the fitting curve coefficients.

For B20; $c=860.73 ; d=-0.508 ; R^{2}=0.9811$. The variation of kinematic viscosity $(v)$ as a function of temperature for different types of fluids is described by means of Andrade type equations as shown in Equation (3) $[4,5]$ :

$$
v=\mathrm{e}^{\left(\mathrm{A}+\frac{\mathrm{B}}{T}+\mathrm{C} / \mathrm{T}^{2}\right)}
$$

The constants $(A, B, C)$ and the regression coefficients $\left(R^{2}\right)$-for B20, the constants are A $=0.1624$; $\mathrm{B}=61.8512 ; \mathrm{C}=-491.0603 ; \mathrm{R}^{2}=0.9623$ [6]. It was observed that the viscosity of the biodiesel-diesel blend increases as the amount of methyl ester increases in the fuel mixture [7]. Another important parameter that needs to be determined for the blend is the cetane number. The cetane number, a commonly used parameter as an indication of the quality of ignition, is measured using a specific test engine (ASTM D 613) or a constant volume combustion apparatus (ASTM D6890) [8,9]. However, both of these techniques are complicated and expensive. Many attempts were made to develop new methods to determine the cetane number of a fuel including calculated cetane index (CCI) [10]. The CCI index is determined-as a function of fuel density at $15{ }^{\circ} \mathrm{C}$ and the T50 distillation curve point-from empirical correlations according to the ASTM D976 and ASTM D4737. In addition, ASTM D4737 takes into account T10 and T90 values in a distillation curve. CCI values of 48.9 and 47 were obtained using ASTM D976 and ASTM D4737, respectively [6]. The low heating value (LHV) is calculated from high heating values (HHV), taking into account the elemental composition of the pure fuels and the enthalpy of the vaporization of water. It was found that the LHV of blends decreases proportionally with biodiesel concentration [6]. The HHV as a function of viscosity, density, and flash point is described by Equation (4):

$$
\mathrm{HHV}=\mathrm{K}_{4}+\mathrm{K}_{3} \mathrm{~V}+\mathrm{K}_{2} \rho+\mathrm{K}_{1} \mathrm{FP}
$$

where HHV is in (MJ/kg), V is the kinematic viscosity (cSt), $\rho$ is density ( $\mathrm{g} / \mathrm{L})$, FP is flash point $(\mathrm{K}), \mathrm{K}_{1}, \mathrm{~K}_{2}, \mathrm{~K}_{3}$, and $\mathrm{K}_{4}$ are coefficient. Biodiesel is reported to have higher heating values of about $42 \mathrm{MJ} / \mathrm{kg}$ compared to about $50 \mathrm{MJ} / \mathrm{kg}$ for diesel fuel. Another important ingredient is the biodiesel oxygen content. The presence of oxygen in biodiesel helps to improve its combustion efficiency and decreases its oxidation potential due to an increase in the homogeneity of oxygen with the fuel during combustion. Biodiesel is reported to have a higher combustion efficiency than diesel fuel [11]. Also, the effect of canola oil derived biodiesel on the improvement of combustion and exhaust emissions was studied using blend concentrations B10, B20, and B30 [12]. As the blend ratio increased, the combustion pressure and the indicated mean effective pressure decreased at low engine speeds, while they increased at moderate engine speeds. Most of the original equipment manufacturer (OEM) dealers and customer service departments showed that the use of up to $5 \%$ biodiesel (B5) is acceptable. However, the pure biodiesel must meet the quality standards specified by the ASTM D 6751 prior to blending $[13,14]$.

In this paper, blends of B0, B2, B4, B6, B8, B10, B12, B15, B18, B20, B25, B35, B50, B75 and B100 were prepared to study the effects of blending on the properties of the blended fuel. Different correlations 
and equations were developed to predict properties such as density, viscosity, flash point, cloud point, pour point, and refractive index. Also, multi-variable models were established using non-linear regression for ignition properties.

\section{Experimental Details}

Commercial biodiesel produced from canola oil was obtained from Milligan Biofuel, Saskatchewan, Canada. Diesel fuel was obtained from the Co-op Refinery in Regina. The main standard properties are shown in Table 1.

Table 1. The fuel properties of biodiesels and diesel fuels [15].

\begin{tabular}{ccc}
\hline Property & Canola Biodiesel & Diesel Fuel \\
\hline Density at $15^{\circ} \mathrm{C} \mathrm{g} / \mathrm{cm}^{3}$ & 0.8828 & 0.8424 \\
Viscosity at $40^{\circ} \mathrm{C}, \mathrm{cSt}$ & 4.3401 & 2.7109 \\
Flash point ${ }^{\circ} \mathrm{C}$ & 107 & 58 \\
Calculated Cetane number & 61.5 & 57.8 \\
Pour point, ${ }^{\circ} \mathrm{C}$ & -8 & -6 \\
Acid number, $\mathrm{mg} \mathrm{KOH} / \mathrm{g}$ & 0.16 & - \\
Free glycerin $\%$ mass & 0.010 & - \\
Total glycerin $\%$ mass & 0.12 & - \\
Ester content $\%$ mass & 99.2 & - \\
Distillation, ${ }^{\circ} \mathrm{C}$ & & \\
$10 \%$ & 350 & 228 \\
$50 \%$ & 352 & 283 \\
$90 \%$ & 359 & 350 \\
End point & 382 & 372 \\
\hline
\end{tabular}

Predetermined quantities of biodiesel were mixed with diesel fuel on a volume basis to obtain a wide range of biodiesel-diesel fuel blends of $0 \%, 2 \%, 4 \%, 6 \%, 8 \%, 10 \%, 12 \%, 15 \%, 18 \%, 20 \%, 25 \%$, $35 \%, 50 \%, 75 \%$ and $100 \%$. An overhead stirrer adjusted at 150 RPM was used to provide mechanical mixing ( $5 \mathrm{~min}$ ) of the different prepared blends. The properties of diesel fuel, the biodiesels and the blends, were determined using standard ASTM methods as follows: density at $15{ }^{\circ} \mathrm{C}$ (ASTM D941), viscosity at $40^{\circ} \mathrm{C}$ (ASTM D445), flash point (ASTM D93), cloud point (ASTM D2500) and pour point (ASTM D97). Since the dispensing of fuel is measured by volumetric means, variations in the fuel density greatly affect the engine performance. Biodiesel density ranges from 0.86 to $0.90 \mathrm{~kg} / \mathrm{L}$ depending on the source raw material. Density is defined as the degree of consistency measured by the quantity of mass per unit volume. The density of the blends in this work was measured at a controlled temperature of $15^{\circ} \mathrm{C}$ according to the ASTM D941 standard. Kinematic viscosity is one of the most important parameters considered while selecting a fuel for an internal combustion engine as it affects the fuel injection system especially at low temperature increases [16]. Viscosity is defined as the extent to which a fluid resists a tendency to flow. The viscosity of the blends in this work was measured at a controlled temperature of $40{ }^{\circ} \mathrm{C}$ according to the ASTM D445 method. High viscosity causes problems in automobile atomization systems while spraying and it is also responsible for deposition and engine wear in the fuel system. Moreover, it also increases the pumping power required to pump the fuel to the engine. Flash point is another important parameter of fuel especially for the safety of its storage and transportation. It is the measurement of the flammability of a fuel and indicates its fire and explosion potential. Flash point is defined as the minimum temperature at which enough vapors are produced above the fuel to form a mixture with air so that a spontaneous ignition can occur if a spark is provided [6]. Flash point in this study was determined using the ASTM D93 standard method with automatic closed cup Pensky-Marten apparatus. Flash point is inversely proportional to volatility of the fuel, and hence biodiesel is expected to have a higher flash point than diesel fuel. Cloud point and pour point are known as the cold flow properties of the fuel, since they highly depend on cold weather conditions, and describe the limitations of certain fuel under these conditions. Cloud 
point is defined as the minimum temperature at which wax cluster or crystal is observed in a cloudy appearance. The cloud point of the blends in this work was determined according to the ASTM D2500 method. Pour point is the temperature at which a fuel loses its ability to flow and the wax becomes semisolid, like a gel losing its flow potential [16-19]. The pour point of the blends in this work was determined according to the ASTM D97 method. Refractive index is the ratio of velocity of light in the vacuum to the speed of light in that medium (oil) [18]. It shows the change in the angle of light when passed through medium, oil, in this case. The refractive index of the blends was determined using ASTM D1218. The physical properties of diesel-biodiesel fuel blend are given in Table 2.

Table 2. The physical properties of diesel-biodiesel fuel blend.

\begin{tabular}{cccccc}
\hline $\begin{array}{c}\text { Blend } \\
\mathbf{( \% )}\end{array}$ & $\begin{array}{c}\text { Density } \\
\mathbf{( k g} / \mathbf{L})\end{array}$ & $\begin{array}{c}\text { Kin. Viscosity } \\
(\mathbf{c S t})\end{array}$ & $\begin{array}{c}\text { Flash Point } \\
\left({ }^{\circ} \mathbf{C}\right)\end{array}$ & $\begin{array}{c}\text { Pour Point } \\
\left({ }^{\circ} \mathbf{C}\right)\end{array}$ & $\begin{array}{c}\text { Cloud Point } \\
\left({ }^{\circ} \mathbf{C}\right)\end{array}$ \\
\hline 0 & 0.84224 & 3.012 & 71 & -30 & -12 \\
2 & 0.84254 & 3.053 & 74.44 & -30 & -12.3 \\
4 & 0.843 & 3.0647 & 72.22 & -27 & -12 \\
6 & 0.84362 & 3.1109 & 73.33 & -27 & -12 \\
8 & 0.8446 & 3.1735 & 73.33 & -27 & -11.5 \\
10 & 0.8455 & 3.2382 & 74.44 & -27 & -11.8 \\
12 & 0.8465 & 3.2912 & 74.44 & -27 & -11.7 \\
15 & 0.8471 & 3.31627 & 75.55 & -27 & -10.7 \\
18 & 0.8478 & 3.3546 & 74.44 & -27 & -10.3 \\
20 & 0.848 & 3.39 & 75.55 & -24 & -10.4 \\
25 & 0.84991 & 3.45 & 77.77 & -24 & -9.9 \\
35 & 0.8535 & 3.6556 & 78.88 & -21 & -9.2 \\
50 & 0.8585 & 3.9865 & 84.44 & -18 & -7.8 \\
75 & 0.86792 & 4.4849 & 98.88 & -18 & -5.5 \\
100 & 0.87654 & 5.2443 & 170 & -12 & -2.4 \\
\hline
\end{tabular}

\section{Results and Discussion}

\subsection{Density}

Figure 1 shows the effect of blending different concentrations of biodiesel with diesel on the resulting blended fuel density. It can be seen that the density increases as the concentration of biodiesel in the blend increases. This increase in density will cause more fuel consumption as fuel is regulated by volume. Also, the heating value of biodiesel is less than that of diesel fuel; hence more fuel will be required to obtain the same amount of energy $[14,15]$. It was found that the maximum absolute error between the experimental and predicted density values to be $0.072 \%$ with an $R^{2}$ value of 0.9985 . Simple Kay's mixing rule (Equation (6)) was used to obtain average blends values [20]. The proposed correlation developed from experiments performed in this current study showed good agreement with the values obtained from literature on waste palm oil biodiesel [21]. The results show that the developed correlations adequately fitted the experimental data with excellent coefficient of correlation (>0.99). However, as the concentration of biodiesel increased beyond $20 \%$ (B20), the error level increased relatively and reached a maximum value of $0.48 \%$ for B100. Equations (5)-(7) represent the correlation used to fit the density experimental data.

$$
\begin{gathered}
\rho(x)=0.000345121 x+0.84174 \\
\rho(x)=\sum_{i=1}^{n} y i \rho i \\
\rho(x)=0.0003 x+0.8423
\end{gathered}
$$

The density of the blend varies from $0.842 \mathrm{~kg} / \mathrm{L}$ for B0 to $0.876 \mathrm{~kg} / \mathrm{L}$ for B100, which satisfies the requirement of ASTM D6751 as shown in Figure 1. Density of the blend B35 is $1.32 \%$ higher 
than the B0 (pure diesel). The blend density is greatly affected by the biodiesel source raw material. Therefore, if the density of biodiesel is low, the final density of the blend will also be lower at high blend concentrations. Figure 1 also shows that blends beyond B50 do not comply with the fuel standard density requirements as per ASTM D7467. The low density directly affects the heating value of the fuel, which ultimately lowers the engine output.

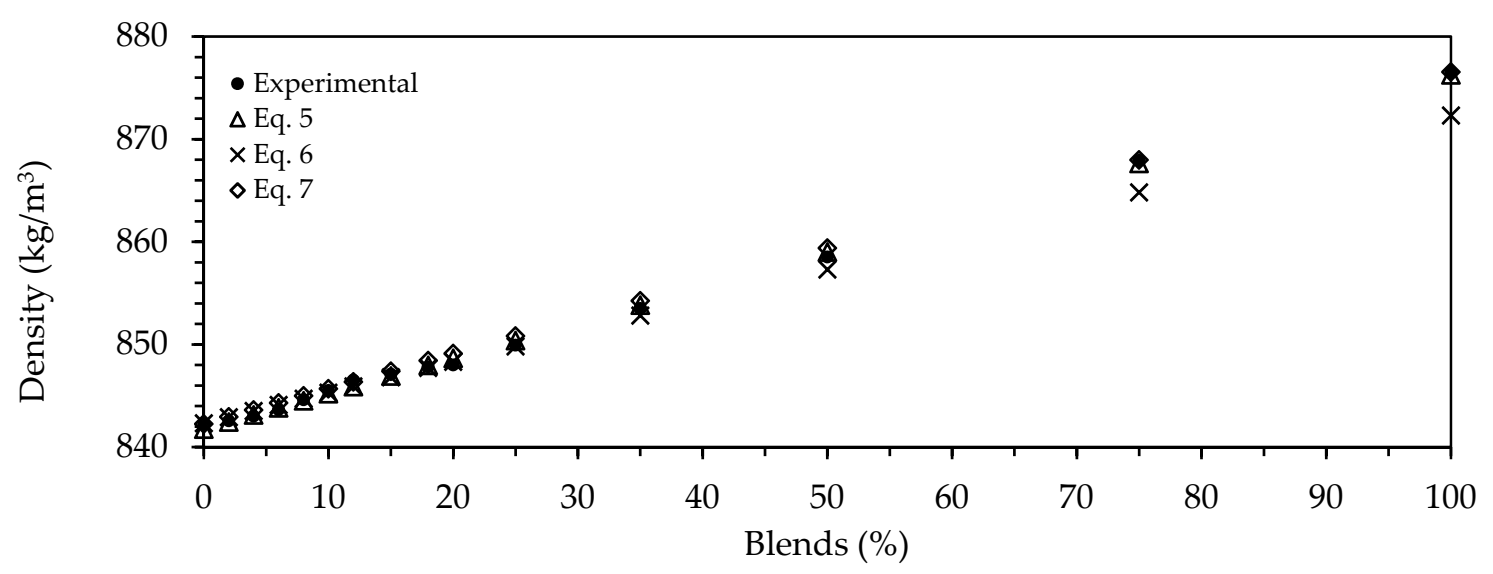

Figure 1. Density variation with biodiesel content.

\subsection{Viscosity}

Viscosity of biodiesel is higher than the conventional diesel and therefore viscosity of a blend is directly proportional to the amount of biodiesel blended $[15,18,22]$. The data were regressed and analyzed using the correlations in Equations (8)-(11). The linear model was tested against the experimental data but it did not yield adequate fit and therefore was not considered further. On the other hand, the second order polynomial equation, Equation (8), and an exponential model Equation (11) are developed in this study and the values were compared with experimental data using the Kay's mixing rule (Equation (9)) and Arrhenius mixing model (Equation (10)). The Arrhenius equation (Equation (10)) is an updated model of Nissan-Grunberg equation (which uses mass \% instead of volume \%). According to the Arrhenius model, it is observed that the interaction parameters in the Nissan-Grunberg equation can be neglected if the mixture components have the same structure and can therefore be used to compare the data because biodiesel and diesel both are non-polar and completely miscible in each other $[6,21]$.

$$
\begin{gathered}
v(x)=0.00006 x^{2}+0.015 x+3.0395 \\
v(x)=\sum_{i=1}^{k} y i v i \\
\log v(\text { blend })=v_{P} \log v_{P}+v_{B} \log v_{B} \\
v(x)=3.0338 e^{0.0054 x}
\end{gathered}
$$

From Figure 2, it can be seen that viscosity increases as the amount of biodiesel in the blend increases. The pure biodiesel had a viscosity $42.56 \%$ higher than that of pure diesel. Except for Equation (9), which gave the maximum absolute error of 4.48\%, the remaining Equations (8), (10) and (11) showed excellent agreement with the experimental data and produced maximum absolute errors of $2.10 \%, 2.18$ and $1.65 \%$, respectively. Even though the correlation coefficient $\left(R^{2}\right)$ value for Equation (8) was highest (0.9972) among all models, the exponential model showed the least error among the four equations. 


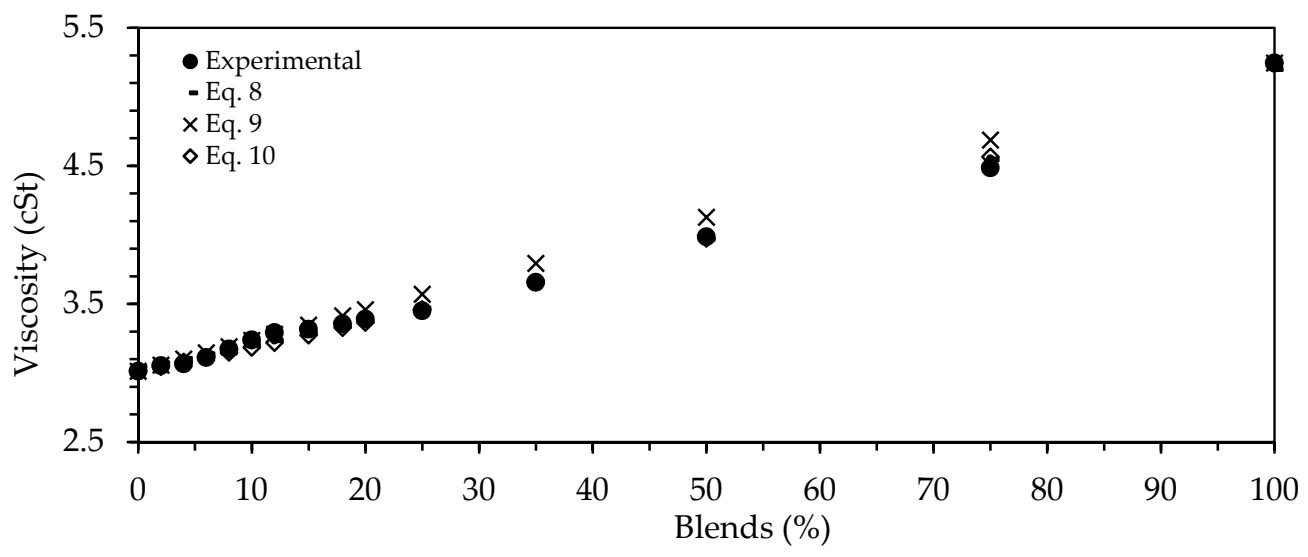

Figure 2. Viscosity variations with biodiesel content.

All prepared blends including B100 fulfill the ASTM D6751 standard requirements for viscosity. Also, blends up to B60 met the ASTM D7467 standard and blends beyond B60 failed to comply with this standard. Since the temperature in Canada during winter can plummet to $-50{ }^{\circ} \mathrm{C}$, the fuel suppliers avoid mixing biodiesel with diesel fuel due to these extreme temperatures that can greatly affect cold flow properties.

\subsection{Flash Point}

Table 2 shows that the biodiesel flash point is almost 2.4 times higher than that of conventional diesel. Figure 3 shows that the flash point gradual (10\% increment) increased as the biodiesel content in the blend increased up to a concentration of B35. For biodiesel concentrations from B50 to B100, the flash point increased exponentially to the maximum of $170{ }^{\circ} \mathrm{C}$. Figure 3 provides a representation of the quadratic and cubic equations. The quadratic model did not fit the data accurately and gave a maximum absolute error of $16.3 \%$, while the cubic model (Equation (13)) showed good agreement with the experimental values, with a maximum absolute error of only $5.1 \%$. Therefore, the cubic model is used to predict the flash point of biodiesel blends.

$$
\begin{gathered}
F P(x)=0.0138 x^{2}-0.5299 x+77.117 \\
F P(x)=0.000251436 x^{3}-0.02191 x^{2}+0.662974 x+70.289
\end{gathered}
$$

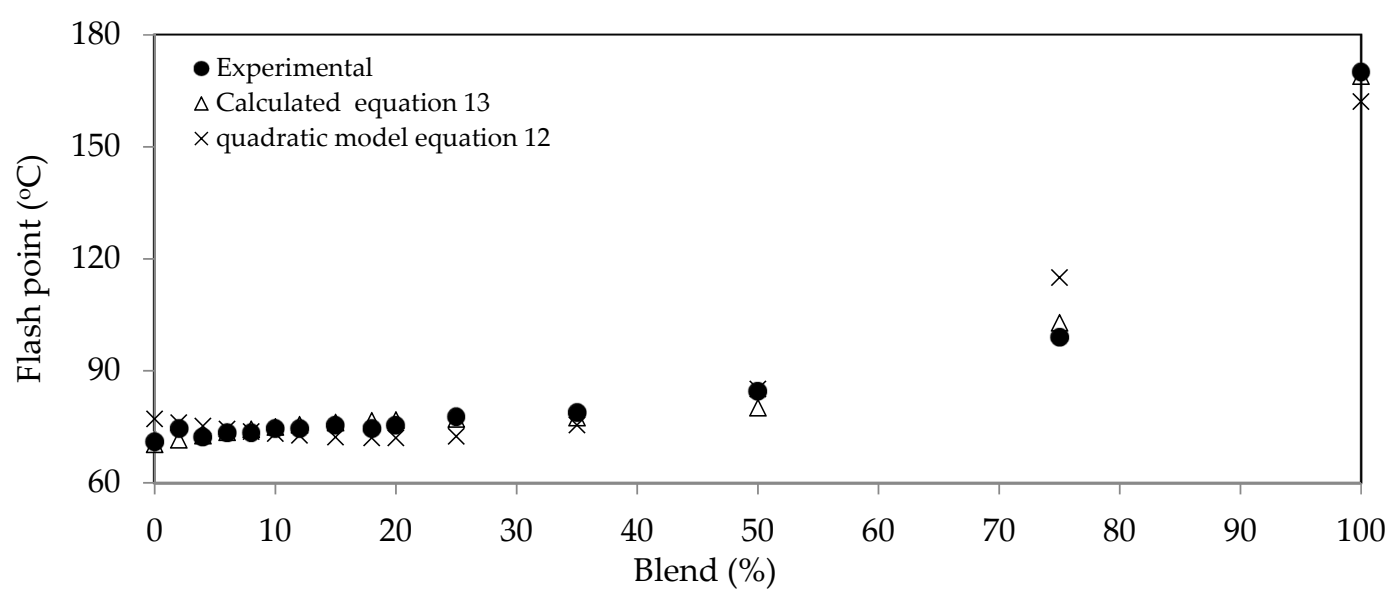

Figure 3. Flash point variation with biodiesel content. 


\subsection{Cloud Point and Pour Point}

Figures 4 and 5 show the experimental and predicted values of pour and cloud point for all prepared blends. Predicted values for cloud point and pour point were obtained using Equations (14) and (15), respectively. It was observed that the cloud and pour points of blends increase as the concentration of methyl ester increases in the diesel fuels. This was attributed to the fact that the cloud and pour points of biodiesel are higher than those of diesel fuel due to the composition of fatty acid present in biodiesel [7]. Cloud and pour points of pure biodiesel and pure diesel were $-2.4,-12$ and $-12,-30$, respectively. These figures show a proportional trend of cold flow properties increasing with biodiesel content. The cloud point increases linearly while the pour point is best fitted with a second order polynomial equation with coefficient of correlation values of 0.9901 and 0.9479 , respectively. The linear relation of the cloud point with respect to biodiesel concentration is in agreement with observations reported in the literature [6]. The effect of biodiesel content on the cloud point was not significantly high from B0 to B25. However, above B35, biodiesel concentration had an appreciable impact on the cloud point. The same phenomenon was observed for the pour point with the most significant increase appears at values greater than B25.

$$
\begin{gathered}
C P(x)=0.0966 x-12.414 \\
P P(x)=-0.0007 x^{2}+0.2339 x-29.344
\end{gathered}
$$

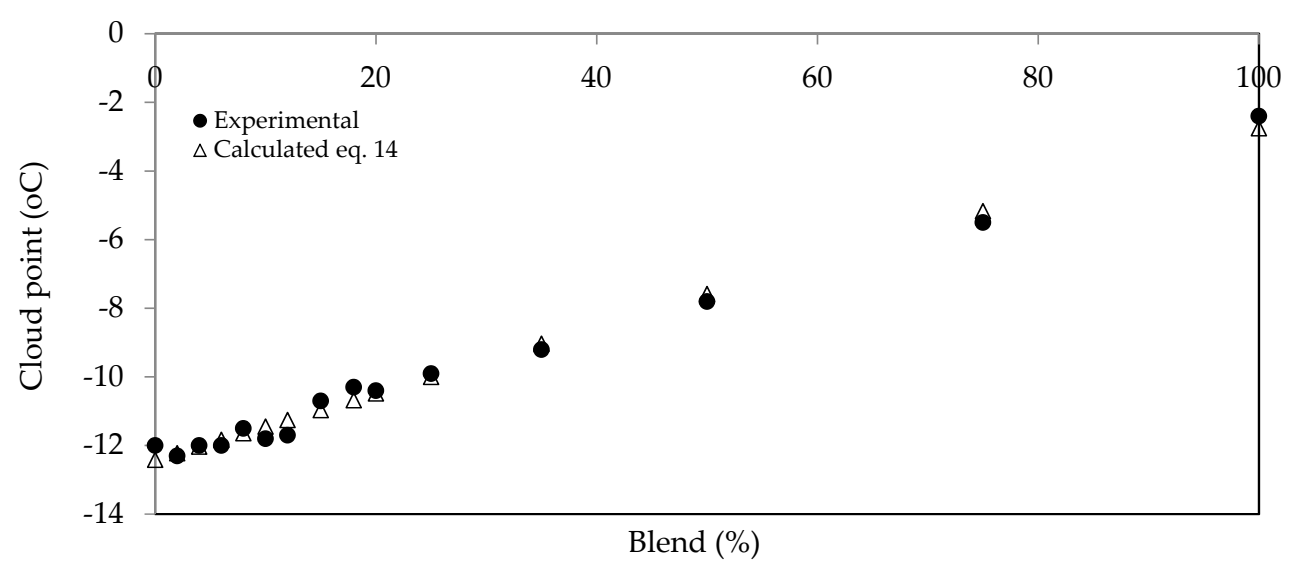

Figure 4. Cloud Point experimental and predicted values.

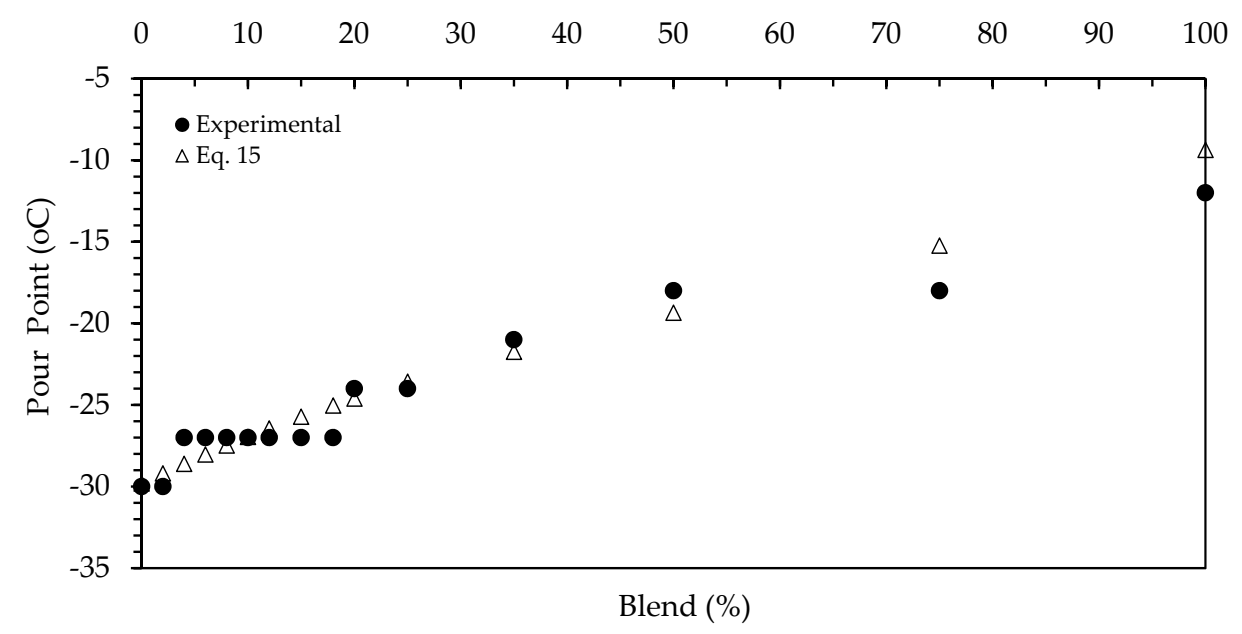

Figure 5. Pour Point experimental and predicted value. 


\subsection{Refractive Index}

Figure 6 shows the experimental and predicted (Equation (16)) refractive index values for the biodiesel blends. It was observed that the refractive index (RI) decreases as the biodiesel content increases for both experimental and predicted data. Figure 7 shows the variation of refractive index for the prepared biodiesel blends at $298 \mathrm{~K}$ and literature data at different temperatures (298-323 K) [23]. For a given biodiesel concentration, it was found that the refractive decreased as the temperature increased. Refractive index is a simple and quick turnaround tool that can be used to develop correlations to predict blended fuel properties such as density, viscosity, heating values, etc.

$$
R I(x)=-0.000113232 x+1.466575205
$$

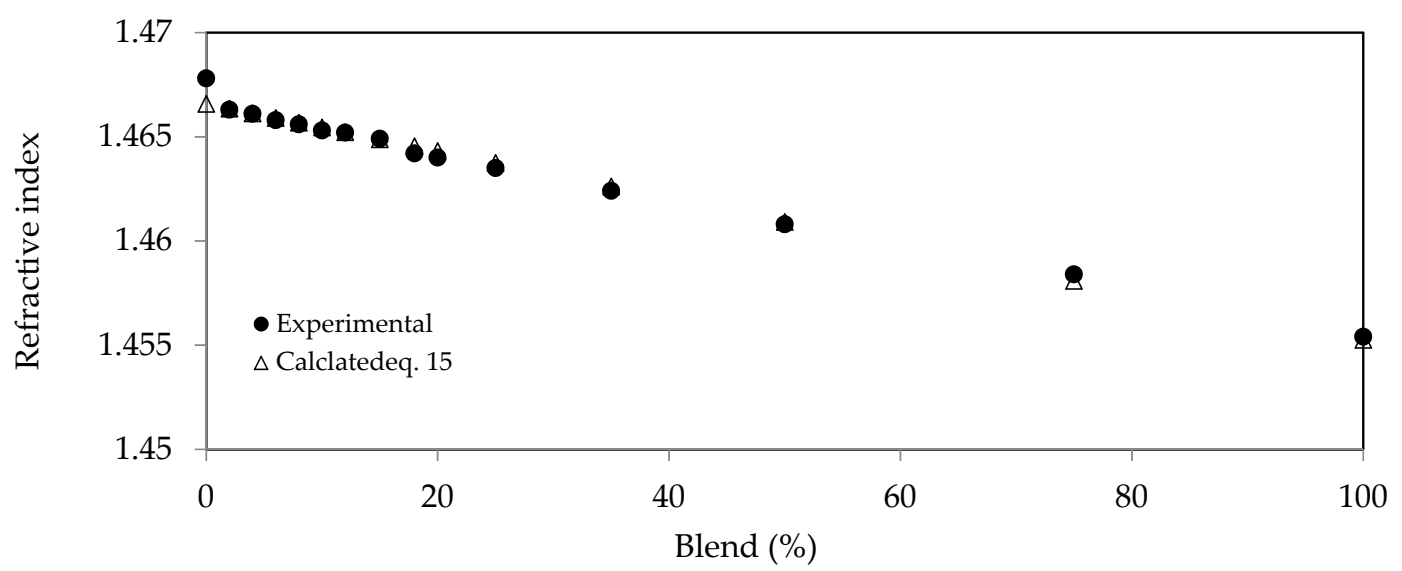

Figure 6. Refractive Index biodiesel blend with predicted value.

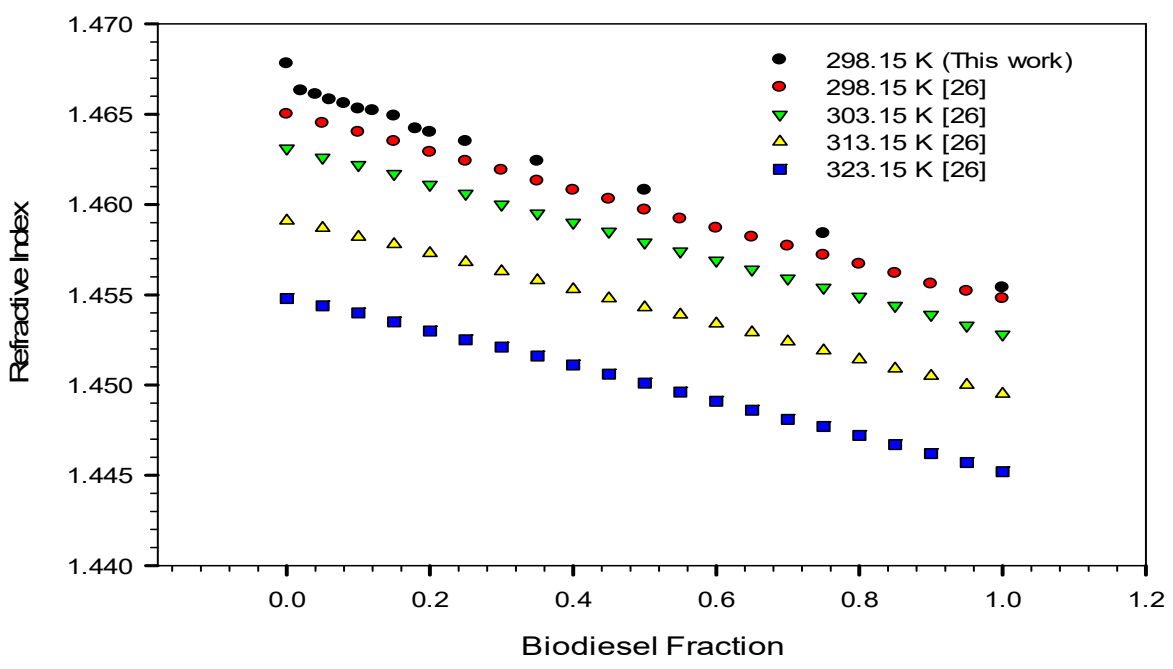

Figure 7. Refractive Index variation of different blend at different temperatures.

Refractive index was used to develop mathematical models for predicting density and viscosity. Figures 8 and 9 show the density and viscosity values plotted using Equations (17) and (18), with corresponding coefficients of correlation 0.98 and 0.97 , respectively. These equations have certain limitations; such as it predicted B0 blend values with a relatively large error $(8.19 \%)$ compared 
to the other blends for viscosity. This can be attributed to the significant change in refractive index from B0 to B2 since the pure diesel (B0) color was opaque.

$$
\begin{gathered}
\text { Density }=-3.0044 R I+5.2481 \\
\text { Viscosity }=-185.41 R I+274.91
\end{gathered}
$$

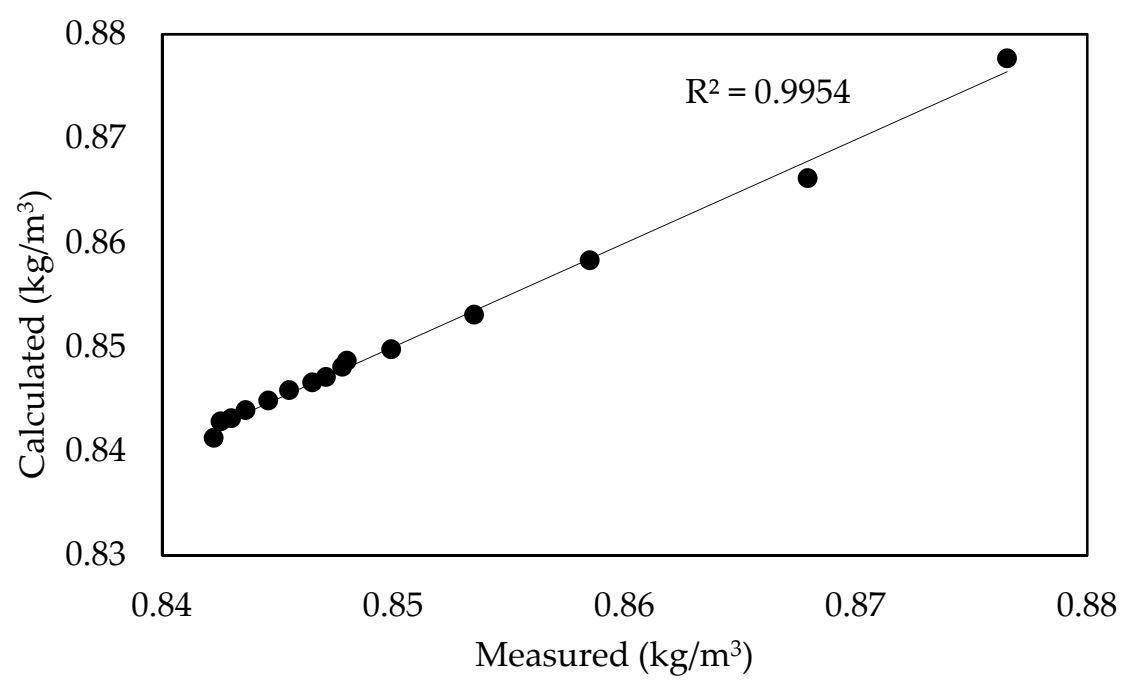

Figure 8. Parity plot for fuel density.

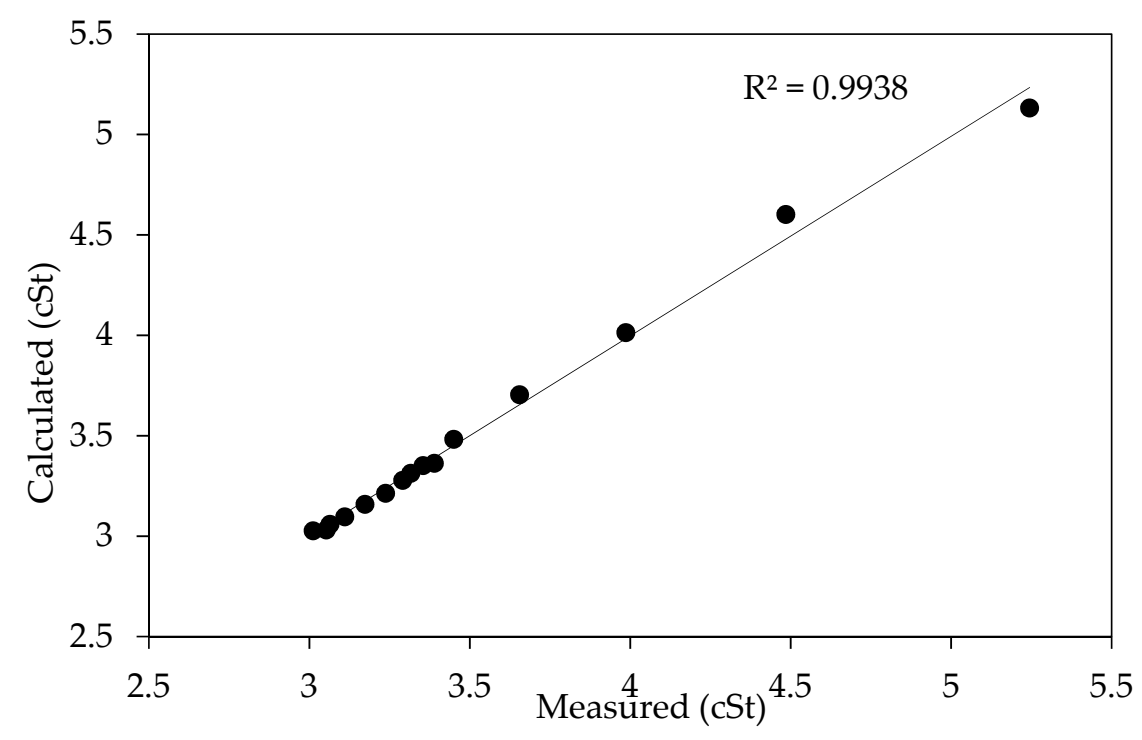

Figure 9. Parity plot for fuel viscosity.

\section{Conclusions}

Biodiesel-diesel blended fuel properties of density, kinematic viscosity, flash point, cloud point and pour points were experimentally determined for a set of pre-defined blends using wide range and small internal blending ratios $(0,2,4,6,8,10,12,15,18,20,25,35,50,75$ and $100 \% v / v)$. The biodiesel used in this study was obtained using off-spec canola feedstock. It is worth noting that increasing kinematic viscosity will have an adverse effect on the diesel oil pumping quality especially in Canadian extreme cold winter conditions. The increasing values of cloud and pour points also has a negative 
effect on the pumping performance of oil circulation as well as on the oil filter due to the formation of heavy materials, which may block the filter, and this may need to have a frequent oil filter change. It is therefore recommended that up to $10 \%$ of biodiesel be added to diesel fuel during summer and no blending during wintertime. In addition, the experimental results showed that the kinematic viscosity and density increased linearly as the concentration of the biodiesel in the blend increases. The pour point and cloud point temperature showed small increases up to $35 \%$ blending ratio and rapid increases in temperature for biodiesel concentrations higher than $35 \%$. The flash point remained almost constant at an average value of $73{ }^{\circ} \mathrm{C}$ for blends less than $20 \%$, above which the values for flash point increased exponentially with biodiesel concentration. Also, different predictive mathematical models were developed for these properties from regressing the experimental data. All models exhibited excellent agreement with experimental data with an average absolute deviation of less than $5 \%$.

Author Contributions: H.I. and I.A.-Z. secured funding, proposed the original idea and provided direction and guidance; U.H. conducted all experimental work; U.H. and I.A.-Z. wrote the first draft of the manuscript; H.I. provided critical revision and wrote the final draft of the submitted manuscript; H.I. and I.A.-Z. supervised the project and provided final approval of the version to be published.

Funding: This research was funded by the Natural Science and Engineering Research Council (NSERC) grant number [RGPIN-402583-2011].

Acknowledgments: The authors would like to thank the Co-op Refinery of Regina for providing access to their labs to perform some of the experimental work needed for this paper. The authors also wish to acknowledge the financial support provided by the Faculty of Graduate Studies and Research (FGSR), the Natural Science and Engineering Research Council (NSERC), Clean Energy Technologies Research Institute (CETRi), and the Canada Foundation for Innovation (CFI).

Conflicts of Interest: The authors declare no conflict of interest.

\section{References}

1. Gerpen, J.V. Biodiesel processing and production. Fuel Process. Technol. 2005, 86, 1097-1107. [CrossRef]

2. Armas, O.; Martínez, S.M.; Mata, M.; Pacheco, C. Alternative method for bulk modulus estimation of diesel fuels. Fuel 2016, 167, 199-207. [CrossRef]

3. Mosesane, M.J.; Mbaya, R.K.; Tshabalala, L.C.; Kalombo, L. Characterization of fuel properties for the biodiesel-petro-diesel blends dosed with the FPC. Glob. J. Res. Eng. J. Gen. Eng. 2015, 15, 1-7.

4. Mustafa, E.T.; Van Gerpen, J.H. The kinematic viscosity of biodiesel and its blends with diesel fuel. J. Am. Oil Chem. Soc. 1999, 76, 1511-1513.

5. Kerschbaum, S.; Rinke, G. Measurement of the temperature dependent viscosity of biodiesel fuels. Fuel 2004, 83, 287-291. [CrossRef]

6. Benjumea, P.; Agudelo, J.; Agudelo, A. Basic properties of palm oil biodiesel-diesel blends. Fuel 2008, 87, 2069-2075. [CrossRef]

7. Alptekin, E.; Canakci, M. Characterization of the key fuel properties of methyl ester-diesel fuel blends. Fuel 2009, 88, 75-80. [CrossRef]

8. Knothe, G.; Matheaus, A.C.; Ryan, T.W. Cetane numbers of branched and straight chain fatty esters determined in an ignition quality tester. Fuel 2003, 82, 971-975. [CrossRef]

9. Knothe, G. Dependence of biodiesel fuel properties on the structure of fatty acid alkyl esters. Fuel Process. Technol. 2005, 86, 1059-1070. [CrossRef]

10. Chevron Product Company. Diesel Fuels Technical Review (FTR-2); Chevron Product Company: San Ramon, CA, USA, 1998.

11. Sivaramakrishnan, K. Determination of higher heating values of biodiesels. Int. J. Eng. Sci. Technol. 2011, 3, 7981-7987.

12. Yoon, S.K.; Kim, M.S.; Kim, H.J.; Choi, N.J. Effects of canola oil biodiesel fuel blends on combustion, performance, and emissions reduction in a common rail diesel engine. Energies 2014, 7, 8132-8149. [CrossRef]

13. National Biodiesel Board, OEM Warranty Statements and Use of Biodiesel Blends over 5\% (B5). Available online: http://biodiesel.org/docs/default-source/ffs-engine_manufacturers/oem-warrantystatement-and-use-of-biodiesel-blends-over-5-(b5).pdf?sfvrsn=6 (accessed on 12 November 2017). 
14. Specifications for Biodiesel, National Biodiesel Board, December 2001. Available online: http://biodiesel.org/ docs / default-source/ffs-production/fuel-quality-policy-update.pdf?sfvrsn=4 (accessed on 10 January 2018).

15. Alptekin, E.; Canakci, M. Determination of the density and the viscosities of biodiesel-diesel fuel blends. Renew. Energy 2008, 33, 2623-2630. [CrossRef]

16. Geacai, S.; Iulian, O.; Nita, I. Measurement, correlation and prediction of biodiesel blends viscosity. Fuel 2015, 143, 268-274. [CrossRef]

17. Wakil, M.A.; Kalam, M.A.; Masjuki, H.H.; Atabani, A.E.; Fattah, I.M.R. Influence of biodiesel blending on physicochemical properties and importance of mathematical model for predicting the properties of biodiesel blend. Energy Convers. Manag. 2015, 94, 51-67. [CrossRef]

18. Chang, A.; Pashikanti, K.; Liu, Y. Refinery Engineering; Wiley-VCH: Weinheim, Germany, 2012.

19. Saxena, P.; Jawale, S.; Joshipura, M.H. A review on prediction of properties of biodiesel and blends of biodiesel. Procedia Eng. 2013, 51, 395-402. [CrossRef]

20. Grunberg, L.; Nissan, A. Mixture Law for viscosity. Nature 1949, 164, 799-800. [CrossRef] [PubMed]

21. Hasan, M.M.; Rahman, M.M. Performance and emission characteristics of biodiesel-diesel blend and environmental and economic impacts of biodiesel production: A review. Renew. Sustain. Energy Rev. 2017, 74, 938-948. [CrossRef]

22. Muñoz, M.; Moreno, F.; Monné, C.; Morea, J.; Terradillos, J. Biodiesel improves lubricity of new low sulphur diesel fuels. Renew. Energy 2011, 36, 2918-2924. [CrossRef]

23. Nita, I.; Geacai, S.; Neagu, A.; Geacai, E. Estimation of the refractive index of diesel fuel+biodiesel blends. Ovidius Univ. Ann. Chem. 2013, 24, 24-26. [CrossRef]

(C) 2018 by the authors. Licensee MDPI, Basel, Switzerland. This article is an open access article distributed under the terms and conditions of the Creative Commons Attribution (CC BY) license (http:/ / creativecommons.org/licenses/by/4.0/). 